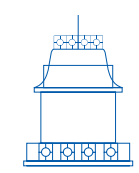

ARTÍCULOS

DE INVESTIGACIÓN

\title{
El Anti-Edipo y el feminismo marxista: elementos para una discusión*
}

\author{
Facundo Nahuel Martín \\ Universidad de Buenos Aires, Buenos Aires, Argentina \\ E-mail: facunahuel@gmail.com \\ Recibido: 5 de febrero de 2020 | Aceptado: 5 de agosto de 2020 \\ https://doi.org/10.17533/udea.ef.n63a07
}

Resumen: Este artículo estudia afinidades no exploradas entre la teoría del capitalismo de El Anti-Edipo y algunas discusiones sobre la reproducción social en el marxismo feminista. Por un lado, el capitalismo, con su movimiento de decodificación de flujos, tiende a disolver a la familia bajo movimientos desterritorializados. Por el otro, supone una reterritorialización edípica (y familiarista) en cuanto separa el parentesco de las relaciones de producción, fundando una escisión históricamente novedosa. La distinción entre axiomática y reterritorializaciones capitalistas, en este contexto, aparece como una forma conceptual adecuada para analizar la relación entre familia y capitalismo en términos feministas-marxistas.

Palabras clave: capitalismo, feminismo, axiomática, reterritorializaciones

* $\quad$ Este trabajo se enmarca en el proyecto de investigación FILOCYT "Relaciones contradictorias entre capitalismo, modernidad y democracia", enmarcado en la Facultad de Filosofía y Letras de la Universidad de Buenos Aires.

Cómo citar este artículo:

Martín, F. N. (2021). El Anti-Edipo y el feminismo marxista: elementos para una discusión. Estudios de Filosofía, 63, 129-149. https://doi.org/10.17533/udea.ef.n63a07

\section{OPEN ACCESS}




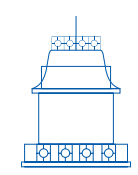

ARTÍCULOS

DE INVESTIGACIÓN

\section{Anti-Oedipus and Marxist feminism: towards a discussion}

Abstract: This article studies unexplored affinities between the theory of capitalism in Anti-Oedipus and some debates on social reproduction in Feminist Marxism. On the one hand, capitalism, with its movement towards the decoding of flows, tends to dissolve the family under deterritorialized movements. On the other, it presupposes an oedipal (and familiaristic) reterritorialization, for it separates kinship from relations of production, founding a historically specific split. The distinction between axiomatic and capitalist re-territorialization, in this context, appears as an adequate conceptual way to analyze the relation between family and capitalism in feminist-Marxist terms.

Keywords: capitalism, feminism, axiomatic, reterritorializations

\section{Facundo Nahuel Martín}

Doctor en Filosofía por la Universidad de Buenos Aires, donde también es docente. Ha publicado los libros Marx de vuelta. Hacia una teoría crítica de la modernidad (2015), Pesimismo emancipatorio. Marxismo y Psicoanálisis en el pensamiento de Theodor W. Adorno (2017) y Teoría crítica de la modernidad. Marxismo, movimientos sociales y proyecto emancipatorio (2020). Investiga la articulación entre transformaciones subjetivas y dinámicas emancipatorias en el marco de una teoría del capitalismo, inscribiéndose ampliamente en la teoría crítica de la sociedad. 


\section{Introducción}

En su introducción a El Anti-Edipo, Eugene Holland marca algunas "intersecciones" posibles para el pensamiento de Deleuze y Guattari: el marxismo, el ambientalismo, el feminismo y los estudios de género. Sin embargo, no presenta una articulación entre las propias intersecciones. Cada una es abordada en sí misma, de manera relativamente autocontenida. La intersección con el marxismo refiere a los problemas del partido y la historia universal, mientras que la intersección con el feminismo y el género se centra en los "aspectos psicológicos" de la dominación patriarcal. Según Holland, Deleuze y Guattari se detienen básicamente en el carácter esquizo, dinámico y transformador del capitalismo con respecto a las relaciones de género, desplegando una discusión ajena a los planteos marxistas-feministas sobre el vínculo entre capitalismo, patriarcado, reproducción social y el trabajo doméstico.

El capitalismo no tiene un código general por medio del cual pudiera imponer una jerarquía de género en la sociedad como un todo (...) Así que, al menos en principio, el género juega un rol pequeño en la construcción de la identidad social bajo el capitalismo. La importante excepción es la no-remuneración del trabajo "reproductivo" de las mujeres (...) que Deleuze y Guattari no discuten (Holland, 1999, p. 377).

Para Holland, El Anti-Edipo permite una crítica de los roles de género binarios y rígidos enmarcados en la familia nuclear, pero que no parece vinculada con la teoría del capitalismo desplegada en el libro. Esa separación entre la significación de El AntiEdipo para los estudios de género y para la reformulación del marxismo permanece en buena parte de la bibliografía secundaria. Existen, entonces, una bibliografía marxista y una bibliografía feminista sobre Deleuze y Guattari, pero ambas difícilmente se entrecruzan. Esto implica que la discusión específica del marxismo feminista, como se ha desarrollado sobre todo durante los años 70, fue generalmente omitida en los análisis sobre estos autores.

Pueden citarse algunos estudios significativos sobre la lectura de Marx y el capitalismo que impregna El Anti-Edipo. El más importante es probablemente Deleuze, Marx and Politics de Nicholas Thoburn (2019). Algunos trabajos como el de Alliez (1997) o la compilación de Jain (2009) han enfatizado la importancia de la lectura de Marx por parte de Deleuze (sabemos que, cuando murió, trabajaba en un libro titulado Grandeza de Marx). Todavía hoy, con todo, las investigaciones sobre Deleuze y Guattari y el pensamiento de Marx son relativamente escasas en comparación con la masiva bibliografía general en torno a estos autores. Exceptuando algunas referencias puntuales, como la discusión del movimiento de salarios para el trabajo doméstico por parte de Thoburn (2019) la discusión feminista no ha estado generalmente presente en los abordajes marxistas de Deleuze y Guattari. 
La bibliografía feminista sobre estos autores es, en cambio, cuantiosa y significativa. Rosi Braidotti (1996; 2005) viene desarrollando una síntesis del pensamiento de Deleuze y el feminismo de la diferencia desde los años 90. Existen también importantes libros al respecto, como Deleuze and Feminist Theory compilado por Ian Buchanan y Claire Colebrook (2000) o Feminist Theory after Deleuze por Hannah Stark (2017). Estas contribuciones han abordado el concepto de devenir mujer, la importancia de la ontología deleuziana para la construcción (y dinamización) de las subjetividades femeninizadas, los vínculos entre el feminismo y las políticas menores, entre otras cuestiones. Sin embargo, no hemos encontrado bibliografía feminista sobre Deleuze y Guattari que se ocupe de su teoría del capital o su lectura de Marx.

En términos más específicos, no parece haber lecturas sobre la importancia de El Anti-Edipo para el marxismo feminista. Con esta noción me refiero al conjunto de pensadoras feministas que, desde fines de los años 60, utilizaron categorías marxistas para explicar los orígenes de la opresión de las mujeres en el capitalismo (Mitchell, 1971; James y Dalla Costa, 1975; Rubin, 1975; Hartmann, 1979; Young, 1981; Vogel, 2013). Los debates marxistas-feministas se centran en la reproducción no paga de la fuerza de trabajo, realizada fundamentalmente en las familias y no reconocida en el ámbito del trabajo asalariado. El debate del feminismo marxista tendió a verse opacado durante los años 90, pero hoy experimenta una moderada reactualización (Arruzza, 2015; Bhattacharya, 2017; Fraser y Jaeggi, 2018). Estas autoras han enfatizado la importancia de la reproducción de la fuerza de trabajo como un ámbito no mercantilizado que es, sin embargo, condición de posibilidad del sostenimiento del capitalismo. En el centro de este planteo está la separación específicamente capitalista entre producción (de valor) y reproducción (de la fuerza de trabajo), una separación que no existe en sociedades previas y que está vinculada de manera sistemática con la familia patriarcal heterosexual como forma dominante de reproducción social en el capitalismo.

En este trabajo voy a intentar una articulación entre el pensamiento de Deleuze y Guattari y cierta discusión marxista feminista sobre la familia como unidad normalizada de reproducción de la fuerza de trabajo. Intentaré destacar una característica general del capitalismo, a saber: la coexistencia contradictoria entre la lógica social de la valorización (fundada en el trabajo creador de valor y las abstracciones del mundo del intercambio) y sus condiciones de posibilidad no inmediatamente mercantiles, como la reproducción de la fuerza de trabajo en el ámbito familiar. En términos de El Anti-Edipo, la escisión mencionada puede comprenderse a partir de la construcción de la axiomática capitalista, que hace enloquecer lo social trastocando los códigos heredados, y las reterritorializaciones que la acompañan permanentemente, restituyendo en nuevos términos los "viejos" códigos del socius precapitalista. Ambas dinámicas (axiomática y reterritorializaciones) poseen lógicas diferentes y en conflicto, aunque pertenecen a la misma forma social y, al fin, se suplementan entre sí. El trabajo creador de valor, sostendré, pertenece a la axiomática del capital, mientras que la familia nuclear patriarcal heterosexual es una de sus reterritorializaciones fundamentales. 
Sobre la base de lo anterior, avanzaré una hipótesis en torno al vínculo entre capitalismo y familia nuclear. De una parte, la axiomática capitalista desaherroja limitadamente la producción deseante y habilita flujos esquizo en lo social. Esto se expresa a su turno en la tendencia del capital a hibridar las identidades de las personas y producir formas proliferantes de la sexualidad bajo la indiferencia a lo cualitativo de la axiomática. De otra parte, la reterritorialización familiar-edípica explica la tendencia del capitalismo a reponer a la familia patriarcal heterosexual como unidad normalizada de reproducción de la fuerza de trabajo, como ha destacado el marxismo feminista. En el vínculo entre axiomática capitalista y reterritorialización edípica, por lo tanto, se juega la tensión entre la lógica abstracta de la valorización (con su poder disolvente sobre la sexualidad, el género y las formas de reproducción social) y sus condiciones de posibilidad no mercantilizadas, entre ellas la familia nuclear (con sus persistentes implicancias patriarcales-heterosexuales). La dinámica del capitalismo sobre el género se prueba entonces contradictoria y compleja, creando situaciones paradojales, dinámicas y contestables.

\section{Desterritorialización I. Capitalismo e identidad gay}

En este apartado voy a desarrollar el primero de estos movimientos contradictorios, recuperando los estudios de D'Emilio (2006) sobre la historia del movimiento gay en Estados Unidos. Con esto intentaré reconstruir un argumento marxista sobre la desterritorialización de la sexualidad en el capitalismo, que tiene un caso testigo en el surgimiento de una "identidad gay" bajo la axiomática capitalista. La generación de una clase de trabajadores libres, desposeídos de los medios de producción y liberados de relaciones de dependencia personal (como el vasallaje, etc.) es precondición del vínculo social del capital, garantizado por las constricciones impersonales, anónimas y universales/abstractas propias del intercambio generalizado. El individuo como trabajador libre e independiente, que se ve obligado a vender su fuerza de trabajo en virtud de la lógica anónima del capital (y no de la violencia ejercida inmediatamente por la clase dominante), se gesta entonces a partir de las mutaciones del vínculo social difundidas por el capital. Bajo la sociedad capitalista, es la vigencia anónima y "abstracta" (independiente de contenidos particulares) del valor la que garantiza el nexo social. Ello significa, también, que el nexo social capitalista posibilita una multiplicidad de trayectorias de vida elegidas de forma independiente por los individuos, aun cuando esa multiplicidad y esa libertad estén mediadas por el carácter reificado de la auto-reproducción del capital. Asimismo, el capital habilita una mirada distanciada del individuo con respecto a su particular forma de vida. Como señala Slavoj Žižek:

Lo que yo soy, mi antecedente social o cultural concreto, es vivido como contingente, ya que en última instancia lo que me define es la capacidad universal 
y 'abstracta' de pensar o trabajar (...) O tomemos el ejemplo ya mencionado de la 'profesión': la noción moderna de profesión implica que yo me concibo a mí mismo como un individuo que no 'nació' directamente en su rol social (Žižek, 2003, p. 114).

Podemos decir que la sociabilidad estructurada en torno al valor en el capitalismo enmarca la emergencia de la contingencia moderna en el marco de la lógica del capital y la imposición del trabajo libre. La época moderna parece caracterizarse como el tiempo de los universales abstracto-formales y, correlativamente, como el tiempo donde lo particular aparece como contingente. El individuo libre del mercado se enfrenta a una multiplicidad de "opciones" de vida contingentes.

John D'Emilio muestra que hay una relación no lineal, pero significativa, entre el avance del sistema de trabajo libre y el desarrollo de la identidad homosexual en la historia de Estados Unidos en el siglo pasado. Los colonizadores europeos que se establecieron en el territorio norteamericano en el siglo XVII poseían en lo fundamental una economía doméstica de unidades familiares autosuficientes. Con la lenta penetración del capitalismo, las personas (primero los varones) fueron abandonando progresivamente el trabajo doméstico para ingresar al trabajo asalariado. Transformaciones posteriores, como la guerra mundial, también abrieron el mundo del trabajo para algunas mujeres. Todo esto condujo -lenta pero sostenidamente- a separar parcialmente al individuo de los lazos familiares y permitirle desarrollar una vida privada independiente. La lenta disolución de la economía doméstica y su reemplazo por el marco "abstracto" del trabajo asalariado sentó las bases objetivas para que algunos individuos pudieran elaborar sus deseos y prácticas sexuales hacia la construcción de una identidad homosexual. En resumen, mientras que las prácticas homosexuales probablemente existan en toda sociedad, la homosexualidad como identidad personal es un producto reciente y específicamente capitalista:

La evidencia de los registros de la corte y la iglesia en la Nueva Inglaterra colonial indica que el comportamiento homosexual masculino y femenino existió en el siglo diecisiete. El comportamiento homosexual, sin embargo, es diferente de la identidad homosexual. Simplemente no había un "espacio social" en el sistema de producción colonial que permitiera a los varones y a las mujeres ser gay. La supervivencia se estructuraba en torno a la participación en el núcleo familiar. Ciertamente había actos homosexuales -sodomía entre los varones, 'obscenidad' entre mujeres- en los cuales las personas se involucraban, pero la familia era tan dominante que la sociedad colonial carecía incluso de la categoría de homosexual o lesbiana para describir a una persona (D’Emilio, 2006, p. 64).

El capital, parece, subordina el nexo social inmediato de la comunidad, la familia (u otras formas de dependencia personal, como el vasallaje) al nexo social universal y abstracto del intercambio generalizado (lo que no significa que los lazos comunitarios 
dejen de existir, sino que pierden el carácter de "mediadores" fundamentales de la vida social). El estudio de D'Emilio permite comprender el proceso dual del capital sobre el vínculo social. Por un lado, el reemplazo de formas de dominación personal o directa por el vínculo impersonal y reificado del capital totaliza las relaciones sociales bajo un sujeto global que constriñe las posibilidades de autodeterminación de las personas. Por el otro, las relaciones impersonales y cuasi-objetivas abren algunas nuevas posibilidades para los individuos, en la medida en que estos pueden, si bien bajo el corset de la lógica del capital, elegir parcialmente sus trayectorias de vida de manera independiente. Esto explica el carácter desterritorializante del capital sobre la sexualidad, que prolifera y se multiplica bajo la lógica abstracta de la valorización. Las personas Ilegan a construir sus identidades a partir de procesos desestructurados en términos de una tradición determinada, donde proliferan dinámicas no gobernadas por códigos específicos, sino por una axiomática abstracta que podemos identificar con la ley del valor.

Ahora bien, ¿no hay ningún lazo positivo entre la familia patriarcal, la norma heterosexual y el capitalismo?, ¿La constricción capitalista de las posibilidades de autodeterminación social se limita a la lógica compulsiva de la valorización, sin tener determinaciones de género? Por el contrario, hay una relación intrínseca y contradictoria entre el capital y la familia patriarcal heterosexual, en virtud de la cual aquél posibilita movimientos sociales que cuestionan esta, pero al mismo tiempo la legitima implícitamente como forma social dominante:

He argumentado que la relación entre capitalismo y familia es fundamentalmente contradictoria. Por un lado, el capitalismo continuamente debilita la fundación material de la familia, haciendo posible para los individuos vivir fuera de la familia, y para las lesbianas y varones gays se posibilita el desarrollo de su identidad sexual. Por otro lado, el capitalismo necesita empujar a varones y mujeres en la estructura de familia, al menos de manera suficientemente duradera como para producir la nueva generación de trabajadores/as. La elevación de la familia al punto de preeminencia ideológica garantiza que la sociedad capitalista reproducirá no solamente niños/as, sino también heterosexismo y homofobia. En el más profundo sentido, el capitalismo es el problema (D’Emilio, 2006, p. 71)

El capitalismo no se limita a pluralizar las trayectorias de vida de los individuos. Tampoco basta decir que el capitalismo pluraliza las relaciones sociales, pero manteniéndolas bajo el molde abstracto de la valorización. En los términos de El Anti-Edipo, que explicaré más abajo, el capitalismo no se limita a desterritorializar la sexualidad y el género. En cambio, el capital impone específicamente la norma "familiar" y heterosexista como patrón social. El rol de la familia patriarcal como garante de la reproducción de la fuerza de trabajo es fundamental en este punto. Para ampliar esta discusión, pasaré a continuación a discutir el aporte del marxismo feminista. 


\section{Reterritorialización I. Capitalismo y patriarcado}

Los estudios de D'Emilio permiten situar los efectos desterritorializantes del capitalismo sobre la sexualidad, vinculando la difusión del trabajo asalariado con la de la identidad gay. Sin embargo, el propio D'Emilio advierte que el capital coarta esos efectos en su dinámica intrínseca, en cuanto presupone la familia nuclear (con sus implicancias patriarcales heterosexuales) como forma de reproducción social. Esto significa que también existe una reterritorialización capitalista de la sexualidad y el género, vinculada a la reproducción de la fuerza de trabajo en la familia nuclear moderna. El capital es contradictoriamente desterritorializante y reterritorializante: si libera a los individuos de las relaciones de dominación personal, también presupone a la familia heterosexual patriarcal como forma de reproducción social. Este planteo remite a las discusiones del marxismo feminista, que intentaré reconstruir someramente en este apartado. El debate entre Heidi Hartmann e Iris Young constituye una referencia clásica al respecto. Hartmann (1983) presenta lo que sería conocido como teoría del sistema dual: capitalismo y patriarcado serían dos sistemas de dominación relativamente autónomos entre sí, capaces de experimentar relaciones de tensión pero que se han acomodado recíprocamente a lo largo del tiempo. "Sea o no la división patriarcal del trabajo, dentro y fuera de la familia, intolerable «en última instancia» para el capital, lo que sí es cierto es que está configurando al capitalismo hoy" (Hartmann, 1983, p. 22). Esta autora enfatiza la coexistencia de capitalismo y patriarcado como dos sistemas históricamente articulados, aunque lógicamente independientes. Para Iris Young, en cambio, capitalismo y patriarcado no configuran dos sistemas sociales independientes sino un único "patriarcado capitalista". La unicidad sistémica se debe a que el capitalismo pone la separación, históricamente única, entre los vínculos de parentesco y la producción de valor.

Una de las características que definen al capitalismo es la separación de la actividad productiva de las relaciones de parentesco con la consiguiente creación de dos esferas de vida social. Este planteamiento y el mostrar cómo esta separación ha creado una situación histórica única para la mujer, ha sido uno de los logros principales del análisis feminista socialista (Young, 1992, p. 4).

En la sociedad capitalista, las actividades reproductivas (la reproducción de la fuerza de trabajo) se escinden de las productivas (la producción de valor), separando la economía de las relaciones de parentesco y constituyendo la familia nuclear burguesa como unidad de la reproducción social. Esta tesis no implica que se pueda derivar lógicamente, partiendo de la forma mercancía o la ley del valor, la dominación masculina heterosexual. Con todo, es necesaria una teoría unitaria porque no puede definirse la dominación patriarcal que caracteriza a la sociedad moderna en términos autónomos con respecto a las categorías organizadoras de la sociedad capitalista. Las formas de opresión de género específicas de la modernidad están imbricadas con las 
categorías sociales capitalistas, en particular con la separación entre la producción y la reproducción.

Este debate recibió una sistematización importante de parte de Lise Vogel (2013), cuyos aportes han sido retomados por Titthi Bhattacharya (2017) y Nancy Fraser (2018). Para Vogel, "fue relativamente fácil demostrar que el trabajo doméstico no produce valor" (2013, p. 23). En cambio, se trata de una forma de trabajo "indispensable para la reproducción de las relaciones sociales capitalistas" (Vogel, 2013, p. 24) en cuanto "la reproducción de la fuerza de trabajo es una condición de la producción" (Vogel, 2013, p. 144). Con el capitalismo, entonces, se genera una separación históricamente determinada entre producción de valor y reproducción de la fuerza de trabajo, emergiendo la familia nuclear patriarcal heterosexual como ámbito privilegiado para esta última. El trabajo doméstico feminizado es subalternizado en este esquema dual, no reconocido como trabajo y separado de la economía productora de valor.

Bhattacharya ha profundizado estos planteos, señalando que necesitamos abandonar el lenguaje de "esferas separadas" para la producción y la reproducción sociales (2017, p. 76). Por el contrario, la teoría de la reproducción social se refiere a la reproducción de la sociedad de conjunto, incluida la de la fuerza de trabajo, como momentos diferenciados pero mantenidos en unidad bajo el capitalismo. "La reproducción social del sistema capitalista (...) no se trata de la separación entre una esfera económica y una no económica, sino de cómo el impulso de las condiciones de producción capitalistas condiciona lo asílllamado no-económico" (Bhattacharya, 2017, p. 75). La unidad de ambos circuitos se funda en el hecho de que los trabajadores deben vender su fuerza de trabajo al capital y obtener bienes de consumo bajo la forma de mercancías. Esto significa que no reproducen su vida en una esfera autónoma, sino en un circuito integrado a la producción capitalista, pero con una dinámica propia (fundada en trabajar para consumir). La reproducción de la fuerza de trabajo se realiza fuera de la producción de valor, constituyendo un circuito diferente, integrado en una totalidad sistémica con ésta.

Nancy Fraser, si bien no pertenece estrictamente al marxismo feminista, ha incorporado varios aportes de esta corriente en su pensamiento reciente, produciendo una síntesis que se destaca por su claridad conceptual. Fraser avanza una primera definición "ortodoxa" del capitalismo para, sobre esa base, construir caracterizaciones más complejas. El capitalismo supone 1) la división de la sociedad entre una clase de productores y una de propietarios; 2) la mercantilización institucionalizada del trabajo asalariado; 3) la dinámica compulsiva del capital como valor que se valoriza; 4) la alocación del excedente social y los factores de producción mediante el mercado (Fraser \& Jaeggi, 2018). El capital es caracterizado como "sujeto" del proceso de valorización (Fraser \& Jaeggi, 2018, p. 31), en cuanto su dinámica recursiva y automatizada toma a los seres humanos como sus "peones". Asimismo, esa dinámica de acumulación tiene por presupuestos la división de la sociedad en clases y la compra-venta de la fuerza de trabajo. Estos cuatro rasgos iniciales pretenden dar cuenta del carácter históricamente 
determinado de la sociedad capitalista, de su especificidad histórica o de los rasgos singulares que la caracterizan y diferencian de otras formas sociales preexistentes.

Ahora bien, ni la dinámica de la valorización, ni la venta de fuerza de trabajo como mercancía, ni la división de la sociedad en clases bastan para caracterizar al capitalismo, una forma social que excede estructuralmente a la relación de capital y sus ramificaciones internas. Sencillamente, "la sociedad no puede ser mercancías hasta el final [all the way down]" (Fraser, 2012, p. 1). Por el contrario, hay "condiciones de posibilidad no mercantiles" para la existencia de mercancías (Fraser, 2012, p. 8). Siguiendo críticamente a Karl Polanyi, Fraser cuestiona la tesis de la universalización capitalista de la forma mercancía, con sus patrones objetivos y subjetivos (2014). Por el contrario, el marco institucional del capitalismo produce una diferenciación de ámbitos que son las "condiciones de trasfondo" [background conditions] del proceso de valorización.

La primera condición de trasfondo o división institucional del capitalismo que Fraser destaca, siguiendo precisamente al marxismo feminista, es la reproducción de la fuerza de trabajo. En la sociedad capitalista, la reproducción de la fuerza de trabajo es realizada en buena medida (aunque no totalmente) en un marco doméstico no mercantilizado, y descansa predominantemente sobre el trabajo no reconocido de las mujeres. Este trabajo reproductivo es "absolutamente necesario para la existencia de trabajo asalariado" (Fraser \& Jaeggi, 2018, p. 45). Incluye también los procesos de subjetivación básicos que dan lugar a la formación de comunidades y la interacción social significativa. La división entre producción de mercancías y reproducción social es una condición "completamente generizada" del capitalismo (Fraser \& Jaeggi, 2018, p. 46). Esta división institucional también es históricamente específica: en otras sociedades históricas, la actividad social y económica se orienta directamente a la producción para la subsistencia como tal, no separándose en los ámbitos escindidos de la producción de valor y la reproducción social. La reproducción de la fuerza de trabajo delimita una condición de trasfondo no mercantilizada del mercado capitalista, que posee dinámicas normativas propias.

En el artículo "Contradictions of capital and care", Fraser sostiene que el capitalismo tiene una profunda, estructural, tendencia a la crisis de reproducción social (Fraser, 2016, p. 100). Las contradicciones sistémicas del capitalismo no se despliegan solamente dentro de la acumulación de capital (caída de la tasa de ganancia, sobreproducción, etc.). El capitalismo posee contradicciones estructurales y tendencias a la crisis también en la interacción entre la reproducción de la fuerza de trabajo y la producción de mercancías. "Por una parte, la reproducción social es una condición de posibilidad para la acumulación de capital sostenida, por la otra, la orientación del capitalismo a la acumulación ilimitada tiende a desestabilizar el proceso de reproducción social en el que se basa" (Fraser, 2016, p. 100). La separación entre producción de mercancías masculinizada y reproducción de fuerza de trabajo feminizada conlleva una relación contradictoria entre las dos (Fraser, 2016). Esta combinación de separación, 
dependencia y rechazo es fuente de constante inestabilidad social, en cuanto la dinámica de la acumulación tiende a socavar las bases de la reproducción social que, al mismo tiempo, presupone como su condición institucional. El capitalismo, entonces, perpetúa la interacción dinámica y contradictoria entre la producción de mercancías y la reproducción de la fuerza de trabajo no mercantilizada, como circuitos diferenciados pero relacionados. En este plano aparecen las reterritorializaciones capitalistas de la sexualidad y el género, articuladas en torno a la familia nuclear como forma de reproducción social. Hablamos aquí de un proceso reterritorializante en cuanto el capitalismo no solo abre y pluraliza lo social dentro de los límites de la valorización, sino que también recodifica la sexualidad bajo los patrones bien determinados de la familia nuclear como unidad de reproducción social.

\section{Desterritorialización II. El capitalismo y la axiomática}

La breve reconstrucción de arriba nos permite abordar la relación entre capitalismo y familia nuclear (con sus implicancias patriarcales y heterosexuales) en términos de separaciones y correspondencias. El capitalismo, entendido como economía orientada al plusvalor y estructurada por la relación de capital, parece en principio indiferente al género y la sexualidad. La explotación de la fuerza de trabajo y la perpetua valorización del valor, a diferencia de las formas de dominación de clase precapitalistas, no se basan en normas tradicionales ni relaciones de dominación personales que establezcan jerarquías directas entre las personas. En esto radica el movimiento desterritorializante del capital, que más arriba vinculé con los estudios de D’Emilio. Sin embargo, la imagen del capitalismo como una sociedad gobernada solo por las abstracciones del valor y la mercancía se complica en cuanto incluimos en el análisis la reproducción de la fuerza de trabajo. La propia separación entre trabajo creador de valor y trabajo doméstico es históricamente determinada: las sociedades precapitalistas, orientadas a la producción para el consumo, no escinden una parte de sus actividades como trabajo y otra parte como actividades reproductivas. Asimismo, esta separación específica del capitalismo está generizada (i.e., marcada por el género), lo que constituye los géneros modernos en términos económicos, ligando lo masculino con el trabajo creador de valor y lo femenino con la reproducción social, la familia, etc. Existe, por lo tanto, una forma de patriarcado capitalista fundada en la separación entre trabajo y reproducción social. Aquí opera una reterritorialización capitalista de la sexualidad y el género, que entra en colisión periódica con las dinámicas desterritorializantes.

El debate de arriba puede organizarse conceptualmente a partir de la distinción de Deleuze y Guattari entre axiomática y reterritorializaciones capitalistas. Estos autores reconstruyen lo que llaman la máquina capitalista civilizada, fundamentalmente, en el capítulo 3 de El Anti Edipo, sumando algunas otras referencias en otros puntos del texto y también algunas aclaraciones de las clases recuperadas en Derrames. El capitalismo es 
caracterizado por la decodificación y desterritorialización de los flujos que estructuran el socius y su reemplazo por una axiomática abstracta. Los autores diferencian tres grandes máquinas históricas que organizan el registro de flujos sobre el socius: la territorial, la despótica y la capitalista. La primera se inscribe sobre el "cuerpo completo" de la tierra, organizando los flujos por códigos de alianza y filiación. La segunda, levantada junto con el Urstaat, sobrecodifica los flujos que discurren sobre un socius organizado en torno al cuerpo del tirano. El capital, en cambio, se funda por primera vez en una generalizada desterritorialización y decodificación de los flujos. Habilita, bajo condiciones precisas, un movimiento cabalmente formal de las inscripciones sobre el socius, organizadas en torno a una axiomática abstracta que no es, precisamente, un código más. La máquina capitalista es diferente de las anteriores, "se encuentra en una situación totalmente nueva: la decodificación y desterritorialización de los flujos" (Deleuze y Guattari, 1972, p. 41). En un principio, el capital decodifica los flujos de dinero y trabajo (habilita la circulación libre de dinero en multiplicidad de formas e instituye la figura del trabajador libre, no atado por lazos de dominación directa). En esa medida, desterritorializa también los flujos de trabajo, en cuanto presupone la libre movilidad geográfica de los trabajadores (en comparación con la inscripción territorial del siervo de la gleba, por ejemplo). Con esta transformación, el capital bloquea la posibilidad de que un código determinado organice todo el campo social.

El capital, en su condición de abstracción cuantitativa, no pone un código sino una axiomática formal que organiza lo social. Tiende a abolir todas las formas determinadas de inscripción de los flujos sobre el socius, desplazando a los códigos y poniendo en su lugar una axiomática abstracta que lo fluidifica todo, salvo su propia dinámica formal. Como sostiene Thoburn, "el socius capitalista no se basa en la identidad" (Thoburn, 2019, p. 28), que es fundamentalmente distinta de las máquinas precapitalistas (despóticas o primitivas).

En las clases vertidas como Derrames, Deleuze precisa el argumento. "La originalidad del capitalismo es que ya no cuenta con ningún código. Hay residuos de código, pero ya nadie cree, ya no creemos en nada" (Deleuze, 2010, p. 27). El capitalismo se caracteriza por cierto cinismo con respecto a los códigos, por cierta indiferencia hacia ellos. Decodifica los flujos, lo que constituye su especificidad histórica, porque no tiene "régimen estructural particular, autoridad o configuración de la vida que mantener" (Thoburn, 2019, p. 92), sino que lo subsume todo en el único objetivo abstracto de la producción para el valor. Sin embargo, el socius capitalista debe constantemente reintroducir códigos determinados que limitan su dinámica abstractiva, entre ellos, las clases sociales y sus categorías que fijan identidades rígidas (trabajadores, capitalistas). Luego, el capital opera una subversión general, pero limitada de las codificaciones de flujos precapitalistas. General, porque instaura un socius donde los flujos se rigen por una axiomática abstracta. Limitada, porque no puede prescindir de las limitaciones a la decodificación impuestas por sus propias formas, tanto por su axiomática (producción para el valor) como por las recodificaciones y reterritorializaciones específicas que esa axiomática produce. 
El capital, a partir de lo anterior, tiende al límite esquizofrénico de todo lo social y a la vez desplaza ese límite. Para Deleuze y Guattari, la producción deseante como tal es esquizofreniza, en cuanto deviene sin detenerse en una identidad ni meta fija. El capitalismo guarda una relación específica con la producción deseante porque en cierto sentido la habilita o amplifica en comparación con las máquinas territoriales y despóticas previas. "El capitalismo tiende hacia un umbral de decodificación que deshace el socius en provecho del cuerpo sin órganos y que, sobre este cuerpo, desencadena los flujos del deseo en un campo decodificado" (Deleuze y Guattari, 1972, p. 41). Se produce entonces una enorme carga esquizo: el capital "tiende con todas sus fuerzas a producir al esquizo como el sujeto de los flujos decodificados sobre el cuerpo sin órganos" (Deleuze y Guattari, 1972, p. 41), que luego el propio capital debe reprimir, restituyendo secundariamente territorialidades y códigos propios de la modernidad (estados, naciones, familias), citando a todas las formas de codificación previas (la ideología capitalista es "una pintura abigarrada de todo lo que se haya creído jamás", Deleuze y Guattari [1972, p. 42]).

Los flujos decodificados que se derraman sobre el socius capitalista se caracterizan por la falta de un objeto determinado. Con el capital, el carácter ateleológico de la producción deseante emerge en toda su potencia sobre lo social. Si el psicoanálisis descubre la esencia subjetiva del deseo (independiente de sus objetos), la economía política clásica descubre la esencia subjetiva de la riqueza en el acto de trabajar, con independencia de sus objetos contingentes y determinados. En este aspecto, la economía política refleja el proceso real del capital: "desterritorialización de la riqueza bajo la forma capitalista, que hace que sea comprendida en función de una actividad productora cualquiera, y no de un elemento determinado que sería la tierra o el Estado" (Deleuze, 2010, p. 147). En este punto se hace evidente que los axiomas instituidos por el capital son irreductibles a cualquier código. "El primer aspecto de la inmanencia capitalista es entonces una especie de axiomática contable consistente en una instauración de relaciones diferenciales entre flujos descodificados y desterritorializados" (Deleuze, 2010, p. 117). La axiomática difiere de los códigos porque representa la actividad subjetiva (el dinamismo de la producción deseante) con independencia de cualquier objetivación determinada. El capital lidia directamente con flujos libres de toda codificación específica, esto es, libres de todo encuadramiento previo en un conjunto de objetos determinado. En esto radica su "especificidad radical" en términos históricos:

Una axiomática no funciona como un código. Los códigos son los que relacionan el trabajo y el deseo a objetividades subyacentes - sea un sistema territorial, sea un sistema despótico-, mientras que la axiomática es un sistema de relaciones que representan una actividad subjetiva en tanto tal, una actividad desterritorializada. Esto vuelve a retomar la hipótesis de la que hemos partido este año; cuando los flujos son descodificados, se sustituye un código por una axiomática, es decir, 
por un sistema de relaciones diferenciales entre flujos descodificados (Deleuze, 2010, p. 147).

La esquizofrenia es la tendencia más íntima y característica del capital, al tiempo que constituye su límite insuperable. El capital tiende hacia ese límite y lo exorciza constantemente, empujándolo más allá. Los autores comparan este movimiento con la tendencia decreciente de la tasa de ganancia. El capital propulsa la tendencia continuamente, al tiempo que la refrena. La tasa de ganancia tiende a bajar, pero no llega al punto cero que coincidiría con el fin del capitalismo. Ese límite es desplazado una y otra vez, de modo que el juego de aplazamiento pasa a ser inherente a la dinámica de la propia sociedad capitalista: se acerca a su límite y lo repele una y otra vez.

El capitalismo surge por el encuentro contingente, singular e interactivo entre procesos de decodificación y desterritorialización de flujos con orígenes independientes. "Deseos decodificados y deseos de decodificación, los hubo siempre" (Deleuze y Guattari, 1972, p. 265). Lo que da paso al capitalismo es el encuentro preciso entre ciertos flujos decodificados, cuya unidad en cierto momento se genera de modo contingente. Ninguna necesidad histórica gobierna su alumbramiento, dado fundamentalmente por el encuentro contingente entre flujos de trabajadores desterritorializados y dinero decodificado.

En el corazón de El capital, Marx señala el encuentro de dos elementos "principales": de un lado, el trabajador desterritorializado, devenido trabajador libre y desnudo, teniendo que vender su fuerza de trabajo; del otro lado, el dinero decodificado, devenido capital y capaz de comprar esa fuerza de trabajo (Deleuze y Guattari, 1972, p. 266).

El trabajo libre, desligado de las ataduras tradicionales a la tierra y al señor, por ende desterritorializado, se encuentra contingentemente con el dinero liberado de las codificaciones antiguas, convertido en capital. Este encuentro habilita una decodificación masiva de flujos: reorganización de los medios de producción bajo la lógica del capital, pérdida de medios de consumo de los trabajadores por la disolución de la familia y la corporación, decodificación del propio trabajador por la introducción de máquinas en la producción, desterritorialización de la riqueza por la abstracción monetaria, decodificación de los flujos de producción por el capital mercantil, decodificación del Estado por el capital financiero, decodificación de los medios de producción por el capital industrial (Deleuze y Guattari, 1972). El capital disuelve todas las formas tradicionales y heredadas de organización de la producción, instituyendo un movimiento fluido y sin bordes de cuerpos trabajadores, dinero, medios de producción, etc. "La inscripción comercial y monetaria permanece sobrecodificada e incluso reprimida por las características y los modos de inscripción previos de un socius considerado bajo su modo de producción específico, que no conoce y no reconoce al trabajo abstracto" (Deleuze y Guattari, 1972, p. 269). Siguiendo a Marx, el trabajo abstracto puede leerse 
retrospectivamente como una categoría completamente simple y transhistórica, que sin embargo solo adquiere realidad social "práctica" en el capitalismo. La abstracción monetaria se libera de los códigos tradicionales y alcanza entonces a todo el cuerpo social, penetrando en la esfera de la producción y haciendo del trabajo mismo una realidad abstracta en su forma de existencia práctica.

El capital, en suma, esquizofreniza por doquier, abre la producción deseante, y al mismo tiempo vuelve a cerrarla bajo el peso de su axiomática, produciendo un marco formal y abstracto pero astringente donde todas las máquinas de codificación previas son sacrificadas, para que todo el socius sea sometido a una axiomática formal. Por eso el capital esquizofreniza, pero lo hace de manera acotada, precisa, selectiva y limitada:

Todo es demente en el sistema: es que la máquina capitalista se nutre de flujos decodificados y desterriorializados; ella los decodifica y desterritorializa todavía más, haciéndolos pasar por un aparato axiomático que los combina, y en los puntos de combinación produce pseudo códigos y reterritorializaciones artificiales. Es en este sentido que la máquina capitalista no puede prescindir de suscitar siempre nuevas territorialidades y de resucitar nuevos Urstaat despóticos. El gran flujo mutante del capital es pura desterritorialización, pero opera en tanto una reterritorialización (Deleuze y Guattari, 1972, p. 374)

En síntesis, el capitalismo rompe las codificaciones de flujos antiguas (territorial y despótica), reemplazándolas por su propia axiomática formal y abstracta. En ese movimiento doble, se coloca como límite exterior de todas las sociedades anteriores (que conjuran la decodificación de flujos por todos sus medios). A la vez, el capitalismo tiene un límite interno en su propia axiomática, que no puede romper sin desorganizarse y entrar en crisis. Al decodificar los flujos y abrir el socius a la producción deseante, esquizofreniza y se acerca a su propio límite, que desplaza una y otra vez hacia afuera. El esquizo es, entonces, el límite absoluto del capital, su tendencia más íntima y más disolvente, a la que tiende continuamente y que no deja de expulsar y conjurar, evitar y producir, en un acercamiento asintótico a la disolución completa, que el propio capital no puede consumar.

La tendencia esquizo de la axiomática se puede vincular, en el lenguaje del marxismo, con la indiferencia del valor a las formas concretas de vida. Esta indiferencia abre la producción deseante, desplegando cargas esquizo sobre lo social. En este movimiento se enmarca la tendencia del capital a desestructurar el género, hibridar las identidades y reconfigurar las sexualidades. En el nivel de la axiomática, el capitalismo aparece como una sociedad dominada por el valor, con su indiferencia cínica frente a las formas de vida cualitativas, las territorializaciones y los códigos. Su dinámica es fija y totalizante, pero puede instanciarse en cualquier forma cualitativa determinada. En esa medida, el capital abre lo social, habilita flujos esquizo y dinamiza las formas del deseo. Esto, a su turno, se expresa en la ruptura de las codificaciones familiares antiguas y la aparición de la persona libre, jurídicamente independiente y que organiza 
su vida bajo la libertad formal del trabajo asalariado. Esa figura, que es característica del proletariado moderno, puede construir biografías variables e inscribir prácticas sexuales en nuevas modulaciones (no preexistentes históricamente) de la sexualidad y el género. El movimiento esquizo, desterritorializante y decodificante del capital, enmarca entonces construcciones subjetivas sexualizadas como la identidad gay estudiada por D'Emilio. Estas nuevas exploraciones de la subjetividad sexuada pueden leerse teóricamente desde la desterritorialización de flujos en el marco del capitalismo como esquizofrenia. Sin embargo, como enfatizaré abajo, el capital también produce reterritorializaciones edípicas y familiares que reponen identidades de género rígidas, patriarcales y heterosexuales.

\section{Reterritorialización II. Edipo y la familia nuclear}

Los códigos tradicionales, sin embargo, permanecen o son reconstituidos en el capitalismo en la forma de arcaísmos sociales refuncionalizados. La axiomática formal no trabaja en el vacío: necesita codificaciones y territorializaciones que le garanticen la continuidad y subsistencia. El capitalismo, en efecto, no decodifica completamente el socius, y no solo reemplaza los flujos codificados por la axiomática. Al definir el capitalismo fundamentalmente por la decodificación de flujos, se presentan las cosas de modo "sumario" (Deleuze y Guattari, 1972, p. 276). Este orden social también instituye reterritorializaciones que le son específicas, reconstruidas bajo su égida peculiar y que se articulan con su lógica. Estas reterritorializaciones son fundamentalmente el Edipo y el Estado.

La producción deseante es sometida al tamiz edípico en las específicas condiciones del capitalismo. Bajo el imperio de las máquinas territorial y despótica, "la reproducción económica no es jamás independiente de la reproducción humana" (Deleuze y Guattari, 1972, p. 313). No existe entonces la familia en el sentido nuclear y privativo que adquiere en la modernidad, sino que esta es "una praxis abierta, una estrategia coextensiva al cuerpo social" (Deleuze y Guattari, 1972, p. 313). Las relaciones de parentesco organizan directamente la producción social en las sociedades precapitalistas. En ese marco, no existe una esfera económica separada de otras actividades sociales. La escisión entre la economía y los lazos de parentesco surge propiamente con el capitalismo, habilitando a la vez la lógica del capital como valor que se auto-valoriza y la "privatización de la familia" (Deleuze y Guattari, 1972, p. 313). La familia nuclear, separada de la reproducción social y económica, constituida como esfera de intimidad, es entonces un resultado de la dinámica social más amplia del capitalismo. A partir de la privatización de la familia como unidad de consumo antes que de producción, se genera la colonización edípica del sujeto en virtud de la cual "cada uno tiene sus propios madre y padre privados" (Deleuze y Guattari, 1972, p. 315, cursivas originales). Edipo viene entonces a poner coto a las posibilidades abiertas que la decodificación capitalista, de otra manera, haría fluir de modo abierto. 
En la institución del Edipo se plasma la mayor reterritorialización capitalista contra los flujos decodificados. El capital, en otras palabras, al tiempo que desterritorializa los flujos, los reterritorializa en la forma de colonización edípica del deseo y privatización de la familia. Si la esquizofrenia es el "límite absoluto de toda sociedad" (Deleuze y Guattari, 1972, p. 317, cursivas originales), en cuanto desata los flujos decodificados y desterritorializados de la producción deseante, el capital, en cambio, aparece como límite relativo, en cuanto decodifica los flujos pero también los axiomatiza y reterritorializa sometiéndolos a su propia dinámica formal y al Edipo. La esquizofrenia habilitada por el capitalismo es también, entonces, su límite exterior: aquello a lo que el capitalismo tiende íntimamente, pero que debe cada vez exorcizar. El capital desplaza una y otra vez sus límites inmanentes, expandiéndose y ampliando su axiomática. El Edipo, en cambio, es el límite interior del capitalismo. "El triángulo edípico es la territorialidad personal y privada que se corresponde con todos los esfuerzos de reterritorialización del capitalismo" (Deleuze y Guattari, 1972, p. 317). La constitución de la sexualidad edípica, encerrada en la triangulación familiar, es la contracara general de la axiomática del capital. Esta máquina social que decodifica los flujos de manera masiva y general aparece también como la responsable de la gran reterritorialización, encerrando el deseo en el molde edípico.

La reterritorialización edípica de la sexualidad y el deseo es fundamental porque se vincula con las disyunciones exclusivas que organizan otras reterritorializaciones importantes. "Edipo es un medio de integración en el grupo" (Deleuze y Guattari, 1972, p. 123). Las identificaciones edípicas entre padre, jefe y otras figuras de autoridad favorecen la constitución de formas segregativas de lo social. Estas formas no coinciden con la división en clases, creando en cambio modos de pertenencia segregativos que refuerzan identificaciones autoritarias, reaccionarias, etc. Las formas segregativas de investidura libidinal producen exclusiones violentas de grupos subyugados, reforzando el poder del propio capital. El Edipo se anuda con ellas, constituyendo su salvaguardia en cada individuo. "Edipo depende de esta clase de sentimiento nacionalista, religioso, racista, y no al revés: no es el padre el que es proyectado sobre el jefe, sino el jefe el que se aplica sobre el padre" (Deleuze y Guattari, 1972, p. 123). El capital no reterritorializa por la vía de la ideología, sino por las investiduras libidinales de grupo que producen conjunciones de tipo segregativo. El Edipo como forma de economía libidinal acompaña a estas disyunciones, que se proyectan en él penetrando en la intimidad aparentemente privada y única de cada sujeto.

La temporalidad dinámica de la modernidad capitalista es, por lo anterior, oscilante (Deleuze y Guattari, 1972). De una parte, cargas paranoicas, edípicas y segregativas que refuerzan al estado y la familia produciendo identificaciones de grupo violentas y excluyentes. Del otro lado, la producción deseante esquizofrenizando, discurriendo por flujos desterritorializados y decodificados. La axiomática moderna bascula entre dos polos: la desterritorialización general de los flujos y su reterritorialización por las regresiones al Urstaat, la figura paterna y la autoridad constituida edípicamente. 
"Nacidas de la decodificación y la desterritorialización, sobre las ruinas de la máquina despótica, estas sociedades están atrapadas entre el Urstaat que querrían resucitar (...) y los flujos desencadenados que entran en un umbral absoluto" (Deleuze y Guattari, 1972, p. 309). Entre el desencadenamiento esquizo de la producción deseante y la clausura paranoica del grupo segregativo, entre la liberación y el autoritarismo, oscilan las formas del socius en la modernidad del capital.

Vinculando la conceptualización de Deleuze y Guattari con el marxismo feminista, podemos decir que el Edipo no es solo la forma general de las investiduras segregativas. También se anuda con una forma de familia heterosexual y patriarcal que es específica del capitalismo. Después de todo, en el origen del Edipo encontramos el mismo movimiento social que en el origen del patriarcado moderno: la constitución de la familia nuclear como instancia de reproducción de la fuerza de trabajo, separada de la economía del valor y particularizada. El gran corte capitalista que escinde trabajo creador de valor y trabajo reproductivo instituye el Edipo y, con él, una forma de patriarcado heterosexual que segrega el ámbito doméstico, lo generiza y lo asocia con lo femenino. El capitalismo, entonces, funda a la vez el Edipo y la familia patriarcal heterosexual como formas de reterritorialización de los flujos. Este movimiento entra en contradicción con su tendencia a abrir la producción deseante y generar flujos esquizo. Mientras que la axiomática, en su formalidad, parece indiferente al género, la reterritorialización edípica que la acompaña siempre aparece asociada a un patriarcado heterosexual específico del capitalismo.

\section{Conclusión: Familia nuclear, capitalismo y esquizofrenia}

Es posible intentar una reconstrucción del debate marxista feminista y los planteos de El Anti-Edipo en términos de paralelismo. La axiomática capitalista parece referirse al mundo del trabajo creador de valor, con su lógica recursiva pero abstracta. En efecto, el capital se diferencia de otras formas sociales por su indiferencia a lo cualitativo y por el movimiento perpetuo del valor en su dinámica formal. Como tal, el valor es indiferente a todo valor de uso y supone una desorganización de las formas sociales tradicionales organizadas en torno a lazos de dependencia personal. De ahí la proliferación de modos particulares de consumo, la multiplicación de métodos de producción y la dinamización general de las formas de vida en el capitalismo, que incluye la aparición de relaciones de género y sexualidades no signadas por la familia patriarcal heterosexual (presenté estas tesis en "Desterritorialización I"). En este plano, el trabajo creador de valor aparece como el ámbito de la axiomática, regida por una lógica recursiva y totalizante (la valorización), pero abstracta, proliferante y capaz de producir derivas múltiples en el plano de lo cualitativo. Las personas dominadas por la axiomática deben someter sus vidas a la valorización del valor como lógica auto-moviente del capitalismo, pero no a códigos tradicionales determinados. Dentro de los confines de la axiomática, pueden elaborar 
sus biografías como individuos limitadamente autónomos, no sometidos a la tradición y la autoridad personal. Esto genera las bases sociales para los cuestionamientos a la familia nuclear como unidad social, las sexualidades disidentes con la norma heterosexual y la desorganización parcial del patriarcado en el marco de la sociedad capitalista. Se trata de movimientos esquizo, de fluidificación y pluralización sociales, enmarcados en y habilitados por la gran mutación de las formas sociales dada por el pasaje de sociedades de código a una sociedad axiomatizada, que decodifica y desterritorializa los flujos sobre el socius ("Desterritorialización II").

Sin embargo, el trabajo creador de valor no es socialmente autónomo. No es la única lógica del capitalismo. Por el contrario (como intenté mostrar en "Reterritorialización I"), la economía del plusvalor tiene una serie de condiciones de trasfondo (por utilizar la expresión de Fraser) que le son necesarias e irreductibles, esto es, que no están dadas por las categorías del valor, el trabajo y la mercancía sin más. Entre estas condiciones está la reproducción de la fuerza de trabajo, que no se realiza en el ámbito de la producción de mercancías (no hay una "fábrica que trabajadores" que produzca para el mercado con intención de obtener ganancias). La fuerza de trabajo es reproducida en el ámbito no mercantilizado de la familia nuclear. Esta institución es una invención histórica capitalista, que surge de la separación entre producción y reproducción propia de esta forma social. En las sociedades precapitalistas (según lo planteado en "Reterritorialización II"), como dicen Deleuze y Guattari, el parentesco es coextensivo con lo social, de modo que no existe familia nuclear en sentido moderno. La "privatización" de la familia, entonces, aparece como una condición de posibilidad no mercantil de la dinámica de la valorización. En término de El Anti-Edipo, el movimiento esquizo ligado a la axiomática capitalista descansa a su vez sobre la reterritorialización familar. La separación entre la familia y la economía, entonces, es una condición de posibilidad del capitalismo. En esa separación se anudan el Edipo (que solo aparece en su forma moderna en el capitalismo, con la privatización de la familia) y el patriarcado heterosexual moderno (porque la familia nuclear ha venido a normalizar, también, que la reproducción de la fuerza de trabajo sea garantizada predominantemente por mujeres en hogares heterosexuales).

La separación capitalista y generizada entre producción de valor y reproducción de la fuerza de trabajo, en suma, se inscribe sobre la tensión entre la axiomática y sus reterritorializaciones. Al nivel de la axiomática, o del trabajo creador de valor, el capital aparece como parcialmente esquizo: dentro de sus marcos formales, es abstracto, indiferente a las formas de la sexualidad y ajeno a los modos particulares de vida. Sin embargo, ver al capitalismo solo como axiomática o como dominación abstracta por el valor es parcial y limitado. La valorización reposa sobre condiciones de posibilidad no mercantilizadas, entre ellas el trabajo reproductivo. Cuando aparecen estas condiciones de posibilidad, el capitalismo retoma viejos códigos que posibilitan su solvencia social, refuncionalizándolos en sus propios términos. Así repone y presupone una serie de formas de dominación particulares, no especificadas al nivel del valor abstracto o la 
axiomática. Entre ellas, encontramos la dominación patriarcal heterosexual. Podemos decir, ampliando la terminología de Deleuze y Guattari, que el patriarcado heterosexual moderno es una reterritorialización capitalista, vinculada al Edipo y sus formas subjetivas. Las subjetividades generizadas se producen, entonces, en la interacción entre los flujos esquizo habilitados por la desterritorialización, y las reconstituciones arcaicas dadas por las reterritorializaciones.

\section{Referencias}

Alliez, È. (1997). Questionnaire on Deleuze. Theory, culture and society, 14(2), 81-87.

Arruzza, C. (2014). Remarks on gender. Viewpoint Magazine.

https://viewpointmag.com/2014/09/02/remarks-on-gender/

Arruzza, C. (2015). Las sin parte. Matrimonios y divorcios entre feminismo y marxismo. Sylone.

Artous, A. (1982). Los orígenes de la opresión de la mujer. Editorial Fontamara.

Bhattacharya, T. (2017). How not to skip class: Social reproduction of labor and the global working class. En T. Bhattacharya (Ed.), Social reproduction theory (pp. 68-93). Pluto Press. https://doi.org/10.2307/j.ctt1vz494j.8

Braidotti, R. (1996). Nomadism with a difference: Deleuze's legacy in a feminist perspective. Man and World, 29, 305-314. https://doi.org/10.1007/BF01248440

Braidotti, R. \& Dolphijn, R. (Eds.) (2005). This Deleuzian century. Brill.

Buchanan, I. \& Colebrook, C. (Eds.) (2000). Deleuze and feminist theory. Edinburgh University Press.

Dalla Costa, M. R. \& James, S. (1975). El poder de la mujer y la subversión de la comunidad. Siglo XXI.

D’Emilio, J. (2006). Capitalismo e identidad gay. Nuevo Topo, 2, 50-71.

Deleuze, G. (2006). Derrames. Entre el capitalismo y la esquizofrenia. Anagrama.

Deleuze, G. \& Guattari, F. (1972). L'anti-Oedipe. Capitalisme et schizophrénie. Editions du Minuit.

Delphy, C. (1985). Por un feminismo materialista. El enemigo principal y otros textos. La Sal.

Dhruv J. (Ed.) (2009). Deleuze and Marx. Deleuze Studies (Volume 3). Edinburgh University Press.

Fraser, N. (2012). Can society be commodities all the way down? Polanyian reflections on capitalist crisis. Archive Ouverte de Sciences de l'Homme et la Societé, halshs-00725060f. https://halshs.archives-ouvertes.fr/halshs-00725060

Fraser, N. (2016). Contradictions of capital and care. New Left Review, 100, 99-117.

Fraser, N. \& Jaeggi, R. (2018). Capitalism. A conversation in critical theory. Polity.

Hartmann, H. (1983). Un matrimonio mal avenido: hacia una unión más progresiva entre marxismo y feminismo. Fundación Rafael Campanas. 
http://www.fcampalans.cat/uploads/publicacions/pdf/88.pdf

Holland, E. (2013). Deleuze, Guattariand minor Marxism. https://doi.org/10.1057/9781137352835_7

Holland, E. (1999). Deleuze and Guattari's Anti-Oedipus. Introduction to schizoanalysis. Routledge.

Patton, P. (2011). What is Deleuzian political philosophy? Crítica contemporánea. Revista de Teoría Politica, 1, 115-126.

Rubin, G. (1986). El tráfico de mujeres: notas sobre la «economía política» del sexo. Revista nueva antropología, 30, 95-145.

Sargent, L. (Ed.) (1981). Women and Revolution: A Discussion of the Unhappy Marriage of Marxism and Feminism. Black Rose Books.

Stark, H. (2017) Feminist Theory after Deleuze. Bloomsbury.

Vogel, L. (2013). Marxism and the Oppression of Women. Toward a Unitary Theory. Brill. https://doi.org/10.1163/9789004248953

Young, I. (1992). Marxismo y feminismo, más allá del matrimonio infeliz (una crítica al sistema dual). El cielo por asalto, 2(4), 43-69.

Thoburn, N. (2019). Deleuze, Marx y la política. Marat.

Žižek, S. (2003). ¿Lucha de clases o posmodernismo? Sí, por favor. En J. Butler, E. Laclau, \& S. Žižek (Eds.). Contingencia, hegemonía y universalidad. Diálogos contemporáneos en la izquierda (pp. 105-132). Fondo de Cultura Económica. 